\title{
Aerodynamic Design and Performance Prediction of a Micro Horizontal Axis Wind Turbine Blade
}

\author{
M. Shuwa*, G. M. Ngala, A. M. El- Jummah and F. M. Kajiama \\ Department of Mechanical Engineering, \\ University of Maiduguri, Maiduguri, Nigeria
}

\begin{abstract}
Horizontal axis wind turbine (HAWT) is a rotor dynamic machine that converts some of the kinetic energy in the wind into other forms of energy such as electricity. It is a type of turbine that has its axis of rotation almost parallel to the wind stream. The blade of a HAWT is the most important components of the turbine and its ability to extract energy in a variety of wind speeds depends on the aerodynamic design and geometry of its airfoil orientation. In this work a HAWT blade is aerodynamically designed based NACA 4412 airfoil and wind speed data of the semi-arid region of Nigeria. The design is for a 3 m diameter HAWT rotor with 3 blades. Blade Element Momentum (BEM) theory and Design Foil Workshop software were used for the aerodynamic design for the HAWT blade. The aerodynamic design result shows that the blade thickness is $22.5 \mathrm{~mm}$ at the root of the blade and $11.5 \mathrm{~mm}$ at the tip. The chord length is $110 \mathrm{~mm}$ at the root of the blade, $180 \mathrm{~mm}$ at $160 \mathrm{~mm}$ from the root and $90 \mathrm{~mm}$ at the tip with a tip speed ratio of 5. The blade twist angle is $9.36^{\circ}$ at the root of the blade and $36.05^{\circ}$ at the tip based on a relative wind speed angle of $50.05^{\circ}$. The optimal performance of the blade is recorded at $7^{\circ}$ angle of attack with a maximum coefficient of lift to coefficient of drag ratio of 124 and lift to drag force ratio of 118 at a Reynolds number of $3 \times \mathbf{x 1 0}^{6}$. The blade's performance is predicted based on its ability to extract the optimal energy from the wind. Based the rotor diameter the available optimal power in the wind at $9.5 \mathrm{~m} / \mathrm{s}$ is determined to be 320 watts, $32 \%$ of this power is extracted by the HAWT blade. The results indicate that the HAWT blade has high potentials and it will help in providing renewable energy conversion system for the dwellers of the semi-arid region of Nigeria.
\end{abstract}

Keywords: Horizontal axis wind turbine, Blade design, Performance prediction.

NOMENCLATURE

\begin{tabular}{lll}
$P_{E}$ & - & The Available Power in the wind \\
$P_{m}$ & - & Extractable or Mechanical Power \\
$A$ & - & Swept Area of the Rotor \\
$\rho$ & - & Air Density \\
$v$ & - & Wind Relative Velocity \\
$\alpha$ & - & Blade Twist Angle \\
$r$ & - & Rotor Radius \\
$C$ & - & Chord Length \\
$\omega$ & - & Angular Velocity of the Rotor \\
$\theta$ & - & Angle of Attack \\
$\phi$ & - & Wind Relative Angle \\
$\eta$ & - & Efficiency of the Blade on the Wind Turbine \\
$L$ & - & Blade Span \\
$\dot{r}$ & - & Radial Length of the Blade Element \\
$d \dot{r}$ & - & Increase in Blade Span Length \\
$T_{Q}$ & - & Rotor Torque \\
$\lambda_{r}$ & - & Tip Speed Ratio \\
$C_{P}$ & - & Power Coefficient \\
$C_{L}$ & - & Coefficient of Lift \\
$C_{D}$ & - & Coefficient of Drag \\
$F_{L}$ & - & Lift Force \\
$F_{D}$ & - & Drag Force \\
$R_{e}$ & - & Reynolds Number \\
$B$ & - & Number of Blades \\
$N$ & - & Speed of the Rotor \\
$T_{N}$ & - & Thrust \\
$V_{r e l}$ & - & Wind Relative Velocity \\
$d t$ & - & Change in Blade Thickness \\
$m$ & - & Meter \\
$m m$ & - & Millimeter \\
$W$ & - & Watts \\
$S$ & - & Second \\
& & \\
\hline & - &
\end{tabular}




\subsection{INTRODUCTION}

Wind turbines are rotor dynamic machines that convert some of the kinetic energy in the wind to other useful forms of energy such as electricity. There are two types of wind turbines, horizontal and vertical axis wind turbines. Horizontal Axis Wind Turbines (HAWT) have the axis of rotation of their blades horizontal to the ground and almost parallel to the wind stream, while the Vertical Axis Wind Turbines (VAWT) have the axis of rotation and blades vertically oriented (Ngo and Natowitz, 2009). Most of the wind turbines fall under the category the Horizontal Axis Wind Turbines because they have some distinct advantages such as low cut-in wind speed and easy furling. In general, they show relatively high power coefficient (Rajakumar and Ravindran, 2010; Chandrala et al, 2012).

The blade of a HAWT is the most important components of a wind turbine, because it is the component that extracts some of the kinetic energy in the wind. The blade's ability to extract energy in a variety of wind speeds depends on the aerodynamic design and geometry of its airfoil (Daminia and Petal, 2013). An airfoil means a two dimensional cross-section shape of a wing whose purpose is to either generate lift or minimize drag when exposed to a moving fluid. Lift on a body is defined as the force on the body in a direction normal to the direction of the stream flow and the drag on a body in an oncoming flow is defined as the force on the body in a direction parallel to the stream flow. The geometry of the airfoil determines the blade's interaction with the wind and is vital in determining the magnitude of lift or drag force on the blade. The relationship between the ratio of lift to drag force and angle of attack plays an important role in the aerodynamic design and performance of the wind turbine blade (Kale and Varma, 2014). One of the methods used in HAWT blade aerodynamic design is the Blade Element Momentum Theory (BEM). The theory assumes that a blade can be divided into multiple elements, which can act independently as two-dimensional airfoils. The forces and moments can be calculated separately then summed to obtain the overall blade forces and moments. Moreover, the theory also assumes that wind turbine harvests energy from incoming flow; thereby, the flow is subjected to pressure and moment losses. Using momentum theory, induced velocities from the momentum loss can be calculated. These induced velocities can affect the flow and forces over and on the blade. (Daminia and Petal, 2013; Kale and Varma, 2014; Biadgo and Aynekulu, 2017).

The aim of this work is to aerodynamically design a HAWT blade and predict the performance of the blade within the wind speed range of the semi-arid region of Nigeria at $10 \mathrm{~m}$ height. Aerodynamic design of the blade is based on National Advisory Committee on Aeronautics (NACA) 4412 blade airfoil data and considering a 3 m diameter HAWT rotor with three blades. Blade Element Momentum (BEM) theory is used addresses the HAWT blade aerodynamic design parameters of the blade airfoil. These parameters includes; chord length $(C)$ of the blade airfoil, blade airfoil thickness $(t)$ lift force $\left(F_{L}\right)$, drag force $\left(F_{D}\right)$, wind relative angle $(\phi)$, blade twist angle $(\alpha)$, angle of attack $(\theta)$, tip speed ratio $\left(\lambda_{r}\right)$ and power coefficient of the blade $\left(C_{P}\right)$. Lift coefficient $\left(C_{L}\right)$ and drag coefficient $\left(C_{D}\right)$ of the blade airfoil are obtained from Design Foil Workshop Software for different angle of attacks. Performance of the designed blade is predicted in terms of its ability to extract some the kinetic energy in the wind However, it is expected that an optimum aerodynamic design will help in providing the much needed renewable energy conversion system to a typical household in the semi-arid region of Nigeria.

\subsection{METHODOLOGY}

The baseline for the aerodynamic design of the HAWT blade is the National Advisory Committee for Aeronautics (NACA) 4412 airfoil data. Base on the airfoil data, a modified blade geometry and orientation is aerodynamically design. The aerodynamic design is carried out using the Blade Element Momentum theory. In determining aerodynamic design features of the blade, the blade is divided in to 12 sections and each section is considered independently as two-dimensional airfoil. Aerodynamic design features of the blade airfoil are determined in each section and then summed to obtain the overall blade parameters which determine the blade's ability to extract energy from the wind. The maximum available power in the wind increases with the cube of the wind speed, linear with density and swept area of the rotor. The available energy in the wind based on a predefine rotor diameter is determined from Equation 1 (Polat and Tuncer, 2013).

$$
P_{E}=0.5 \rho A v^{3}
$$

The available wind speed at a given site is therefore often first measured over a period of time before a blade aerodynamic design is initiated. Aerodynamic design and performance prediction of the HAWT blade is based on correlated 30 years annual monthly mean wind speed data of the semi-arid region of Nigeria as obtained from Nigerian Meteorological Agency. However a physical limit exits to the quantity of energy that the blade can extract from the wind and it is a factor that depends on the blade airfoil design and its geometry. Complete extraction of the kinetic energy in the wind would imply zero velocity downwind, but this scenario is not possible. Thus all the kinetic energy in the wind cannot be extracted and this limitation is known as the Bezt limit which state that wind turbine efficiency cannot exceed 59.3\%. Therefore, based on the aerodynamic design of the blade, the predicted extracted or mechanical power $\left(P_{m}\right)$ to be generated by each of the blade section on a three blade rotor is determined from Equation 2 (Peter and Richard, 2012; Shekh and Salman, 2015).

$$
P_{m}=d T_{Q} \omega d r
$$


The efficiency of the blade depends on the ratio of the available power in the wind to the extracted or mechanical power generated by the blade and is called the power coefficient $\left(C_{P}\right)$ determined from Equation 3. But all the kinetic energy in the wind cannot be extracted based on the limitation known as the Bezt limit, which state that wind turbine efficiency cannot exceed $59.3 \%$. The coefficient of performance of the blade will only be 0.593 of its maximum efficiency (Kale and Varma, 2014; Shekh and Salman, 2015).

$$
C_{P}=\frac{P_{m}}{P_{E}}=0.593 \frac{T_{B} \omega d r}{0.5 \rho A v^{3}}
$$

The coefficient performance of a HAWT blade depends on its aerodynamic design and one of the important datum design parameter is the tip speed ratio. It is the relationship between rotor blade velocity and the velocity of the relative wind as in Equation 4. It is also a design parameter that is used in determining the relative wind angle $(\phi)$ and angle of attack $(\theta)$ at a predefined rotor radius (Peter and Richard, 2012; Bai et al, 2013).

$$
\lambda_{r}=\frac{\omega r}{v}=\frac{2 \pi N r}{60 v}
$$

The distribution of the angle of relative wind $(\phi)$ which consists of angle of attack $(\theta)$ and twist angle $(\alpha)$ along the blade sections are determined from Equation 5, 6 and 7 respectively (Peter and Richard, 2012; Shekh and Salman, 2015).

$$
\begin{aligned}
& \phi=\frac{2}{3} \tan ^{-1}\left(\frac{1}{\lambda_{r}\left(\frac{\dot{r}}{r}\right)}\right) \\
& \theta=\tan ^{-1} \frac{2}{3 \lambda_{r}} \\
& \alpha=\phi-\theta
\end{aligned}
$$

The angle of attack is the angle between the incoming flow stream and the chord line of the airfoil as in Figure 1. It is a required input in Design Foil Workshop software to find the values of the lift coefficient $\left(C_{L}\right)$ and coefficient of drag $\left(C_{D}\right)$ of the airfoil at a predetermined Reynolds number $\left(R_{e}\right)$. Coefficient of Lift to coefficient Drag ratio is calculated for angles of attack from $0^{\circ}$ to $12^{\circ}$ for wind speed from 0 to $10 \mathrm{~m} / \mathrm{s}$. Lift and drag coefficients are factors in determining the magnitude of lift $\left(F_{L}\right)$ and drag $\left(F_{D}\right)$ force acting on the airfoil section as shown in Figure1. Moreover other forces acting on the airfoil section as in Figure 1, where thrust $\left(T_{N}\right)$ defined by Equation 10 and torque $\left(T_{Q}\right)$ define by Equation 11 , both are generated by lift $\left(F_{L}\right)$ and $\operatorname{drag}\left(F_{D}\right)$ forces (Shekh and Salman, 2015; Shuwa et al, 2016).

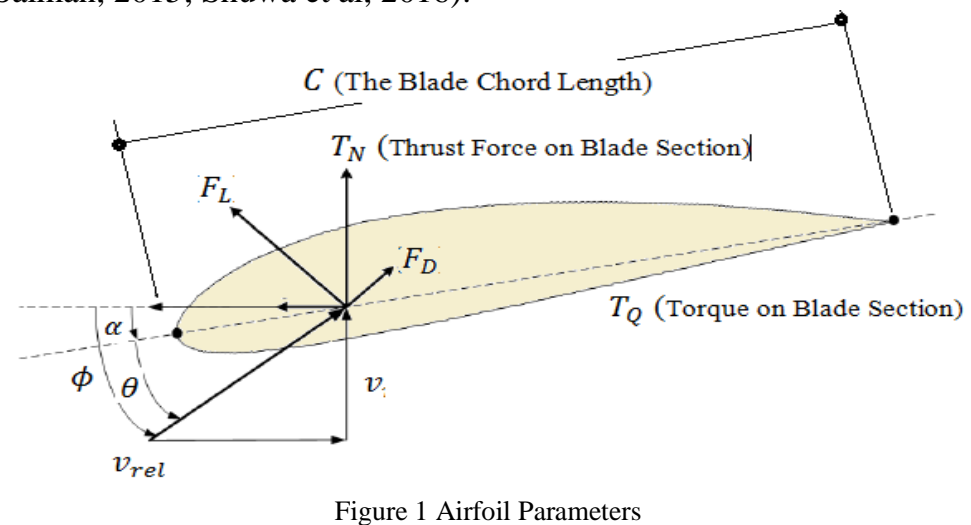

The lift force $\left(F_{L}\right)$ which is the force acting on the blade airfoil perpendicular to the undisturbed wind flow, is determined from Equation 8. The drag force $\left(F_{D}\right)$ which is the force acting on the blade airfoil in the direction of the undisturbed wind flow as given by Equation 9.

$$
F_{L}=\frac{1}{2} \rho v^{2} C L C_{L}
$$




$$
F_{D}=\frac{1}{2} \rho v^{2} C L C_{D}
$$

The lift and drag are available as functions of the angle of attack and the Reynolds number $(R e)$. Also, the magnitude lift and drag force is influence by the blade's angle of attack and the Reynolds number $(R e)$. Reynolds number $(R e)$ as given by Equation 10 is the ratio of inertial forces to viscous forces within a fluid which is subjected to relative internal movement due to different fluid velocity.

$$
R_{e}=\frac{C v_{r e l} \rho}{\mu}
$$

The chord length $(C)$ of a blade airfoil is the length from the leading edge to the trailing edge of a blade cross section that is parallel to the vertical axis of symmetry as shown in Figure 1, and it is obtained from Equation 11.

$$
C=\frac{8 \pi \dot{r}}{B C_{L}}(1-\cos \phi)
$$

The blade thickness $(t)$ along its span is determined as percentage function of the chord length of the airfoil. Base the selected airfoil NACA 4412 the change in thickness of the blade $(d t)$ along the blade span is $12 \%$ of the chord length of each section or divided elements of the blade $(d C)$ as in Equation 12.

$$
d t=0.12 d C
$$

The thrust $\left(F_{N}\right)$ and torque $\left(T_{Q}\right)$ on each of the blade sections or elements are calculated from Equation 13 and 14 respectively and determines the magnitude of the power extracted by the blade. This based on the consideration of the mean axial and rotational velocity in the slipstream and the rate of decrease of momentum of the fluid.

$$
\begin{aligned}
& d F_{N}=d F_{L} \cos \phi+d F_{D} \sin \phi \\
& d T_{Q}=d F_{L} \sin \phi-d F_{D} \cos \phi
\end{aligned}
$$

\subsection{RESULTS AND DISCUSSION}

The micro HAWT blade is aerodynamically designed considering a rotor diameter of $3000 \mathrm{~mm}(3 \mathrm{~m})$ with a blade span of $1200 \mathrm{~mm}(1.2 \mathrm{~m}) 300 \mathrm{~mm}(0.3 \mathrm{~m})$ hub diameter. The design result shows blade airfoil thickness increases as the blade span changes from $0 \mathrm{~mm}$ at the root to $1200 \mathrm{~mm}(1.2 \mathrm{~m})$ at the tip. The airfoil is $22.5 \mathrm{~mm}$ thick at the root, $23.5 \mathrm{~mm}$ thick at maximum chord length of $196 \mathrm{~mm}$ and $85 \mathrm{~mm}$ along the blade span from the root. The thickness of the blade airfoil is $11.5 \mathrm{~mm}$ at the tip of the blade as in Figure 2. The blade twist angle is 24 degrees at the root of the blade and gradually drops to 0 degrees at the tip of the blade as shown in Figure 2. According to Shekh and Salman, 2015 an efficient rotor blade should consist of aerofoil profiles that blend at angle of twist terminating at a circular flange. Ahmed et al, 2011 also added that it may also include tip geometries for reducing losses and facilitated energy production.

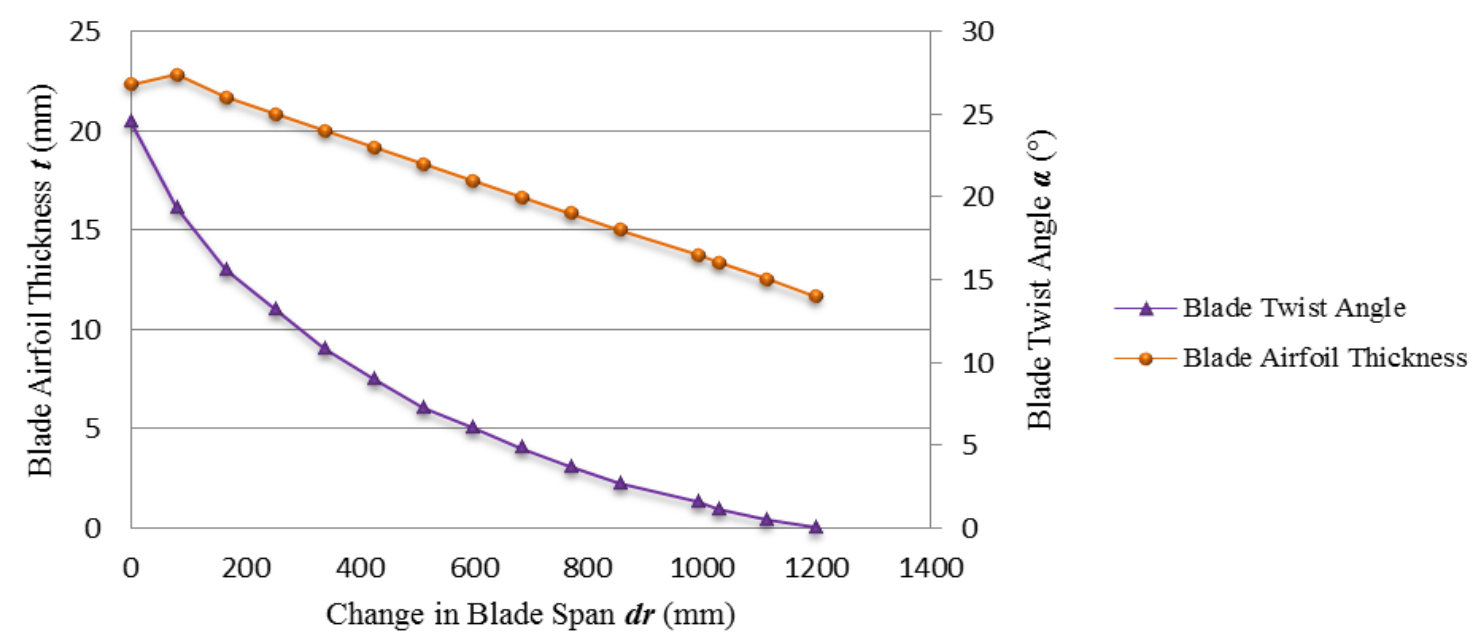

Figure 2 Blade airfoil thickness and twist angle along the blade span 
The blade twist angle is determined based on a wind relative angle of 50.05 degrees at the root of the blade to 9.36 degrees at the tip with a tip speed ratio 5. The aerodynamic design shows an optimum angle of attack of 7 degrees with an optimum coefficient of lift to drag ratio of 124 at Reynolds number $\left(R_{e}\right) 3 \times 10^{6}$ and lift to drag force ratio of 118 as shown in Figure 3.

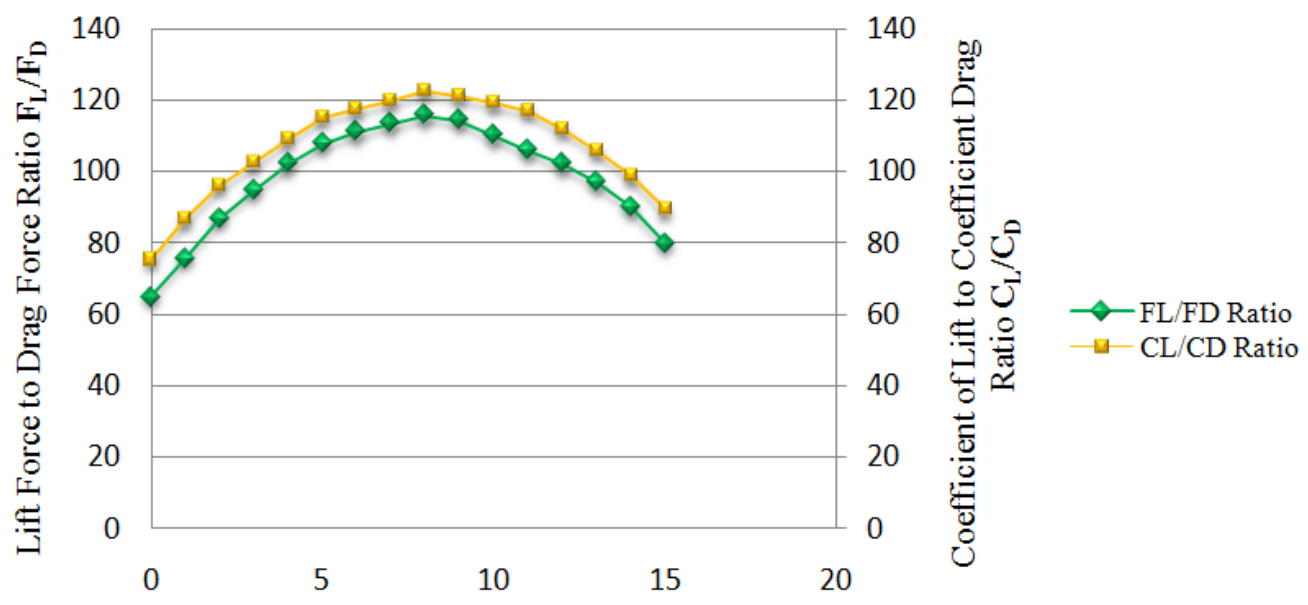

Angle of Attack $\theta\left({ }^{\circ}\right)$

Figure 3 Lift to drag force ratio and coefficient of lift to coefficient of drag ratio at various angles of attack

Rajakumar and Ravindran, 2010 in their work analysis lift and drag forces at different section of a blade for angles of attack from 0 to 12 degrees. Their analysis showed that angle of attack of 5 degrees has high lift to drag force ratio. Biadgo and Aynekulu, 2017 developed an interface prgram to pridict the performance of a HAWT blade. Based on the program optimum angle of attack for small wind turbine blade lies between 4 to 9 degrees depending on the blade geometery and airfoil design, hence 7 degrees anagle of attack of this design is withein the predicted limit. Performance analysis of the blade determined interms of its ability to etract energy from the wind for wind speeds from 0 to $10 \mathrm{~m} / \mathrm{s}$ based on a 3 m micro HAWT rotor. The result shows that the blade extract 32 percent $(32 \%)$ of the power available in the wind. Maximum pridicted power available in the wind at $9.5 \mathrm{~m} / \mathrm{s}$ is 320 Watts and the maximum power extracted by the blade considering a rotor diameter of $3 \mathrm{~m}$ is 102.4 Watts as in Figure 4.

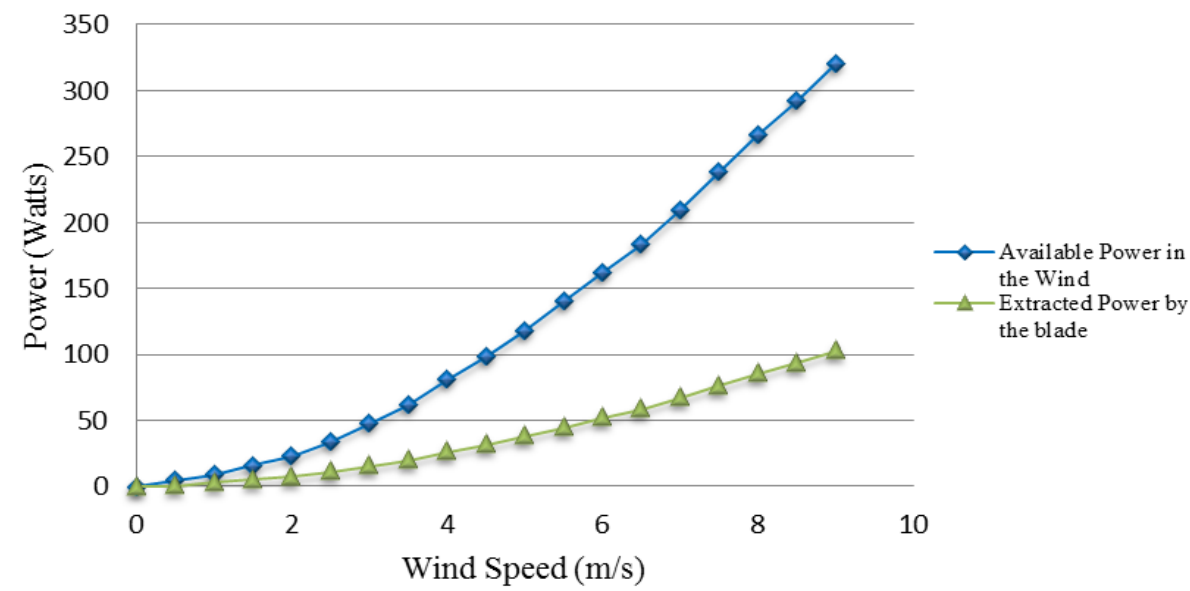

Figure 4 Available power in the wind and extracted power by the blades

Peter and Richard, 2012 indicates that physical limit exist to the quantity of energy that can be extracted which is dependant on the blade design. The magnitude of energy harnessed is a function of the reduction in wind speed over the turbine. This priciple is also reported by Kale and Varma, 2014 and is known as the Betz limit which state that the efficiency of a wind turbine can not exceed $59.3 \%$. 
4.0 CONCLUSION
The micro HAWT blade has been aerodynamically design for a $3 \mathrm{~m}$ rotor and a wind speed range from 0 to $10 \mathrm{~m} / \mathrm{s}$. The blade twist angle is 50.05 degrees at the root and 9.36 degrees at the tip. The active blade span is $1,200 \mathrm{~mm}(1.2 \mathrm{~m})$, maximum chord length is $180 \mathrm{~mm}(0.18 \mathrm{~m})$ and the minimum chord length is $90 \mathrm{~mm}(0.09 \mathrm{~m})$. The blade tip speed ratio is 5 , optimum angle of attack is 7 degrees with an optimum coefficient of lift to drag ratio of 124 at Reynolds number $\left(R_{e}\right) 3 \times 10^{6}$. The designed blade is analysis for performance, the analysis lift to drag force ratio is 118 and the blade is able to extract $32 \%$ of the available power in the wind. However, the micro HAWT blade can further be modified and experimentally analysis for improved performance.

\section{REFERENCES}

[1] Ahmed, M. R., Narayam, S., Zullah, M. A. and Lee, Y. H. (2011). Experimental and Numerical Studies on a Low Reynords Number Airfoil for Wind Turbine Blades. Journal of Fluid Science and Technology, 6: 357-371.

[2] Bai, C., Hsiao, F., Li, M., Huang, G. and Chen, Y. (2013). Design of $10 \mathrm{~kW}$ Horizontal Axis Wind Turbine (HAWT) Blade and Aerodynamics Investigation Using Numerical Simulation. Elselvier Publishers Ltd., 5 (2): 34-40.

[3] Biadgo, A. M. and Aynekulu, G. (2017). Aerodynamic Design of Horizontal Axis Wind Turbine Blades. FME Transactions , 45:647-660.

[4] Chandrala, M., Choubeg, A. and Gupta, B. (2012). Aerodynamic Analysis of Horizontal Axis Wind Turbine Blade. International Journal of Engineering Research and Applications, 2(6):1244-1248.

[5] Daminia, S. and Petal, H. (2013). Performance Prediction of Horizontal Axis Wind Turbine Blade. International Journal of Innovative Research in Science, Engineering and Technology, 2(5): 1401-1406.

[6] Kale, A.S. and Varma, R. N. (2014). Aerodynamic Design of a Horizontal Axis Micro Wind Turbine Blade Using NACA 4412 Profile. International Journal of Renewable Energy Research, 4(1):69-72.

[7] Ngo, C. and Natowitz, J. (2009). Resources, Alternatives and the Environment. New Jersey, USA: John Wiley and Sons Inc.

[8] NIMET. (2017). Meteorological Data. Lagos: Nigeria Meteorological Agency.

[9] Peter, S. and Richard, C. (2012). Wind Turbine Blade Design. Energies, 5: 3425-3449.

[10] Polat, O. and Tuncer, H. I. (2013). Aerodynamic Shape Optimization of Wind Turbine Blades using a Parallel Genetic Algorithm. Elsevier Ltd, 61:2831.

[11] Rajakumar, S. and Ravindran, D. (2010). Computational Fluid Dynamics of Wind Turbine Blade at Various Angle of Attack and Low Reynolds Number. International Journal of Engineering Science and Technology, 2: 11-17.

[12] Shekh, M. and Salman, M. (2015). Design of Wind Energy Turbine Blades: A Review. International Advance Research Journal in Secience, Engineering and Technology, 2(1):193-197.

[13] Shuwa, M., Ngala, G. M and Maina, B. M. (2016). Development and Performance Test of a Micro Horizontal Axis Wind Turbine Blade. International Journal of Engineering Resaerch and Applications, 6(2): 11-17.

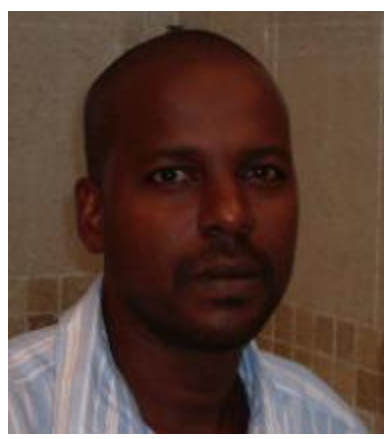

Muhammad Shuwa

Main Author 